\title{
Seoul Virus-Infected Rat Lung Endothelial Cells and Alveolar Macrophages Differ in Their Ability To Support Virus Replication and Induce Regulatory T Cell Phenotypes
}

\author{
Wei Li and Sabra L. Klein \\ W. Harry Feinstone Department of Molecular Microbiology and Immunology, Johns Hopkins Bloomberg School of Public Health, Baltimore, Maryland, USA
}

\begin{abstract}
Hantaviruses cause a persistent infection in reservoir hosts that is attributed to the upregulation of regulatory responses and downregulation of proinflammatory responses. To determine whether rat alveolar macrophages (AMs) and lung microvascular endothelial cells (LMVECs) support Seoul virus (SEOV) replication and contribute to the induction of an environment that polarizes $\mathrm{CD}^{+} \mathrm{T}$ cell differentiation toward a regulatory $\mathrm{T}$ (Treg) cell phenotype, cultured primary rat AMs and LMVECs were mock infected or infected with SEOV and analyzed for viral replication, cytokine and chemokine responses, and expression of cell surface markers that are related to $\mathrm{T}$ cell activation. Allogeneic $\mathrm{CD} 4^{+} \mathrm{T}$ cells were cocultured with SEOV-infected or mockinfected AMs or LMVECs and analyzed for helper T cell (i.e., Treg, Th17, Th1, and Th2) marker expression and Treg cell frequency. SEOV RNA and infectious particles in culture media were detected in both cell types, but at higher levels in LMVECs than in AMs postinfection. Expression of $I f n \beta, C c l 5$, and $C x c l 10$ and surface major histocompatibility complex class II (MHC-II) and MHC-I was not altered by SEOV infection in either cell type. SEOV infection significantly increased Tgfß mRNA in AMs and the amount of programmed cell death 1 ligand 1 (PD-L1) in LMVECs. SEOV-infected LMVECs, but not AMs, induced a significant increase in Foxp 3 expression and Treg cell frequency in allogeneic $\mathrm{CD} 4^{+} \mathrm{T}$ cells, which was virus replication and cell contact dependent. These data suggest that in addition to supporting viral replication, AMs and LMVECs play distinct roles in hantavirus persistence by creating a regulatory environment through increased TgfB, PD-L1, and Treg cell activity.
\end{abstract}

$\mathrm{H}$ antaviruses are negative-strand RNA viruses (family Bunyaviridae) that are maintained in the environment by causing persistent infection in rodent and insectivore hosts. Virus infection of humans results in hemorrhagic fever with renal syndrome (HFRS) or hantavirus cardiopulmonary syndrome (HCPS), both of which are caused by enhanced vascular permeability $(34,45)$. The absence of cytopathic effects in infected human endothelial cell cultures has led to the hypothesis that hantavirus pathogenesis in humans is due to immune-mediated mechanisms targeting the infected cells $(58,67,71)$. Pathogenic hantavirus infection has been hypothesized to cause human vascular leakage by various mechanisms, including sensitizing endothelial cells to vascular endothelial growth factor (VEGF) and downregulating VE-cadherin $(25,69)$, recruiting quiescent platelets to infected endothelial cells (24), increasing endothelial cell surface ICAM-1 and major histocompatibility complex class I (MHC-I) levels that induce natural killer (NK) cell activation (5), or triggering viral specific $\mathrm{CD}^{+} \mathrm{T}$ cell responses that target infected endothelial cells (35). In addition to infecting endothelial cells, hantaviruses infect macrophages and dendritic cells (DCs) in the human host $(48,59,62)$. Because the primary mode of transmission of hantaviruses to humans is through inhalation of aerosolized virus contained in rodent excreta, infection of alveolar macrophages (AMs) may contribute to viral dissemination in humans (33). Patients infected with hantaviruses have elevated levels of proinflammatory cytokines and frequencies of virus-specific $\mathrm{CD} 8^{+} \mathrm{T}$ cells but decreased regulatory $\mathrm{T}$ (Treg) cell activity and Treg cell numbers $(14,35,44$, $47,49,81)$. Concentrations of the regulatory cytokine transforming growth factor $\beta 1$ (TGF- $\beta 1$ ) are also reduced in HCPS patients (9) and in Syrian hamster models of HCPS (65).

In contrast to the severe diseases in humans, hantaviruses cause persistent infection in the absence of pathological disease in their reservoir hosts $(15,43)$. For example, in Seoul virus (SEOV)infected Norway rats (the natural reservoir for SEOV), virus preferentially replicates in the lungs, with SEOV N protein identified in AMs and lung endothelial cells (18). Elevated regulatory responses, including the production of TGF- $\beta 1$ and numbers of $\mathrm{CD}^{+}{ }^{+} \mathrm{CD} 25^{+} \mathrm{FoxP}^{+}$Treg cells in the lungs, is associated with persistence of SEOV in Norway rats and Sin Nombre virus (SNV) in deer mice $(18,19,68)$. In SEOV-infected Norway rats, the increased expression of $T g f \beta$ occurs within $72 \mathrm{~h}$ of infection and precedes the induction of Treg cells in the lungs (18). The cellular source of the early production of TGF- $\beta 1$ and whether this contributes to the induction of Treg cells in the lungs of infected rats are not known. In addition to the induction of regulatory responses, activity along the type I interferon (IFN) pathway and production of proinflammatory cytokines (e.g., interleukin $1 \beta$ [IL-1 $\beta$ ], IL-6, tumor necrosis factor alpha [TNF- $\alpha$ ], and gamma interferon $[$ IFN- $\gamma]$ ) remain at or below baseline throughout SEOV infection in the lungs of male rats $(18,27,37)$. Conversely, in the spleen, proinflammatory and antiviral responses are elevated during acute SEOV infection (18). Infection of bone marrow-derived macrophages (BMDMs) with SEOV suppresses NF$\kappa \mathrm{B}$-mediated inflammatory responses, including TNF- $\alpha$, IL-6, and IL-10, and surface marker (i.e., MHC-II, CD80, and CD86)

\footnotetext{
Received 16 May 2012 Accepted 13 August 2012

Published ahead of print 22 August 2012

Address correspondence to Sabra L. Klein, saklein@jhsph.edu.

Copyright @ 2012, American Society for Microbiology. All Rights Reserved.

doi:10.1128/JVI.01233-12
} 
expression, suggesting SEOV infection suppresses the innate immune response in antigen-presenting cells (APCs) (2).

Virus-infected cells can induce Treg cells. Hepatitis C virus (HCV)-infected human hepatocytes induce activated CD4 ${ }^{+} \mathrm{T}$ cells to preferentially differentiate into Treg cells, which contribute to the maintenance of chronic HCV infection (26). Both macrophages and endothelial cells are capable of inducing naïve $\mathrm{CD} 4^{+}$ $\mathrm{T}$ cells to differentiate into Treg cells $(1,38,41,72)$. Whether hantaviruses productively infect AMs or endothelial cells in reservoir hosts and whether infection of these cells creates a regulatory environment necessary for induction of Treg cells during persistent hantavirus infection have not been determined and formed the basis for the current studies.

\section{MATERIALS AND METHODS}

Animals and cell isolation. Primary cells were isolated from Lewis rats, Brown Norway rats, or Sprague-Dawley rats, all of which are different inbred laboratory strains of Rattus norvegicus. Adult male Lewis rats (60 to 70 days of age) and Brown Norway rats (120 days of age) were purchased from Charles River Laboratories (Raleigh, NC) and maintained in pathogen-free facilities with a constant 14:10 light-dark cycle. AMs were isolated from Lewis rats by bronchial lavage as described previously (63) with modifications. Briefly, the rats were euthanized with $\mathrm{CO}_{2}$. The lungs and trachea were exposed, and an 18-gauge (18G) blunt needle (Small Parts Inc.) was fixed in the trachea with surgical threads. Cold phosphate-buffered saline (PBS) $(5 \mathrm{ml})$ was slowly injected into the lungs using a 5-ml syringe and drawn out. The lavage step was repeated 10 times, and the fluid was pooled and centrifuged at $400 \times g$ for $10 \mathrm{~min}$ at $4^{\circ} \mathrm{C}$ to pellet cells. Splenic $\mathrm{CD}^{+} \mathrm{T}$ cells were isolated from Brown Norway rats using a MagCellect rat $\mathrm{CD}^{+} \mathrm{T}$ cell isolation kit (R\&D Systems). All procedures were performed in accordance with the guidelines of the Johns Hopkins Animal Care and Use Committee (protocol no. RA10H178).

LCM preparation. For culturing of AMs, lung conditioned medium (LCM) was prepared using a previously described method with modifications (13). Freshly isolated lungs from Lewis rats were minced and collected after filtering through a $100-\mu \mathrm{m}$ cell strainer. LCM was obtained by incubating minced lung pieces with complete-growth RPMI 1640 medium (10\% fetal bovine serum [FBS], 2 mM L-glutamine, 1\% penicillin/ streptomycin) at a tissue/medium ratio of 1:4 (vol/vol) for $48 \mathrm{~h}$. The LCM was filtered through a $0.2-\mu \mathrm{m}$ filter and stored in aliquots at $-80^{\circ} \mathrm{C}$.

Rat LMVEC cultures. Primary cultures of male Sprague-Dawley rat lung microvascular endothelial cells (LMVECs) (VEC Technologies, Rensselaer, NY) were grown in complete-growth RPMI 1640 medium (10\% FBS, 2 mM L-glutamine, $1 \%$ penicillin/streptomycin) supplemented with a final concentration of $50 \mu \mathrm{g} / \mathrm{ml}$ endothelial cell growth supplement (ECGS) (BD Biosciences) and $1 \mu \mathrm{l} / \mathrm{ml} 2$-mercaptoethanol (2-ME) (Invitrogen). Tissue culture flasks, plates, and transwell inserts for all LMVEC cultures were precoated with $50 \mu \mathrm{g} / \mathrm{ml}$ fibronectin (Sigma). Experiments were conducted between passages 3 and 9 .

Virus infection and stimulation. AMs or LMVECs were plated in 24 -well tissue culture plates at $2 \times 10^{5}$ or $1 \times 10^{5}$ cells per well, respectively. The cells were mock infected or infected with $200 \mu \mathrm{l}$ per well of diluted SEOV at a multiplicity of infection (MOI) of $0.05,0.5$, or 5 for $2 \mathrm{~h}$. At the end of the incubation, the cells were washed with RPMI 1640 medium, and the infection medium was replaced with complete-growth RPMI 1640 medium supplemented with LCM for AMs or with ECGS and 2-ME for LMVECs. As specified for each experiment, cells and media were collected at 6 h or 1,3 , or 6 days postinfection (p.i.). On days 0,2 , and 5 p.i. (i.e., $6 \mathrm{~h}$ prior to collecting 6 -h samples and $24 \mathrm{~h}$ prior to collecting day 1 , 3 , and 6 samples), recombinant rat IFN- $\gamma$ (PeproTech), lipopolysaccharide (LPS) (Sigma), or poly (I.C) (pIC) (Invivogen) was added to designated wells at final concentrations of $100 \mathrm{U} / \mathrm{ml}, 100 \mathrm{ng} / \mathrm{ml}$, and $1 \mu \mathrm{g} / \mathrm{ml}$ for AMs and $500 \mathrm{U} / \mathrm{ml}, 100 \mathrm{ng} / \mathrm{ml}$, and $10 \mu \mathrm{g} / \mathrm{ml}$ for LMVECs, respectively. Following infection, all experiments were conducted at biosafety level 3 (BSL-3) using protocols approved by the Johns Hopkins Office of Health, Safety, and Environment (protocol no. P9902030113).

Allogeneic $\mathrm{CD}^{+} \mathrm{T}$ cell coculture. For the AM/CD4 ${ }^{+} \mathrm{T}$ cell coculture and LMVEC/CD4 ${ }^{+} \mathrm{T}$ cell coculture experiments, AMs and LMVECs were plated in 24 -well plates at $5 \times 10^{5}$ cells per well and $2 \times 10^{5}$ cells per well, respectively. The cells were mock infected, infected with SEOV at an MOI of 0.5 or 5 , or infected with UV-inactivated SEOV at an MOI of 5 . At the end of incubation, the cells were washed with RPMI medium, and the infection medium was replaced with complete-growth RPMI 1640 medium. Designated wells of AMs or LMVECs were also stimulated with LPS to induce a Th17 response. At $24 \mathrm{~h}$ p.i., the medium was removed, and $\mathrm{CD} 4^{+} \mathrm{T}$ cells were added to the AM culture at $5 \times 10^{6}$ cells per well and to the LMVEC culture at $2 \times 10^{6}$ cells per well in X-Vivo medium (Lonza). For controls, $\mathrm{CD}^{+} \mathrm{T}$ cells were either cultured alone or stimulated with 1 $\mu \mathrm{g} / \mathrm{ml}$ plate-bound anti-rat CD3 (BD Pharmingen) and $5 \mu \mathrm{g} / \mathrm{ml}$ anti-rat CD28 (BD Pharmingen) in the presence or absence of $10 \mathrm{ng} / \mathrm{ml} \mathrm{recombi-}$ nant TGF- $\beta 1$ (R\&D Systems). Cocultured cells were incubated for 4 days.

For LMVEC/CD4 ${ }^{+} \mathrm{T}$ cell coculture experiments using transwell inserts, LMVECs were plated in the lower chambers of transwell plates (24well format) at $2 \times 10^{5}$ cells per well and were mock infected or infected with SEOV at an MOI of 5 , as described above. On the same day as LMVEC infection, $\mathrm{CD}^{+}{ }^{+} \mathrm{T}$ cells were stimulated with $1 \mu \mathrm{g} / \mathrm{ml}$ platebound anti-rat CD3 (BD Pharmingen) and $5 \mu \mathrm{g} / \mathrm{ml}$ anti-rat CD28 (BD Pharmingen) in X-Vivo 15 medium (Lonza). At 3 days after LMVEC infection and $\mathrm{CD}^{+} \mathrm{T}$ cell stimulation, the medium was removed from LMVEC cultures and replaced with $600 \mu \mathrm{l}$ per well of X-Vivo 15 medium. Transwell inserts ( $6.5 \mathrm{~mm}$ with a $0.3-\mu \mathrm{m}$ pore size; Thermo Scientific) were added to designated wells with or without LMVECs in the lower chamber. Activated $\mathrm{CD}^{+}{ }^{+} \mathrm{T}$ cells were added at $5 \times 10^{5}$ cells per well in $100 \mu \mathrm{l} \mathrm{X}$-Vivo 15 medium to the upper chambers of the transwell inserts to eliminate direct contact between $\mathrm{CD} 4^{+} \mathrm{T}$ cells and LMVECs in the lower chambers. As controls, activated $\mathrm{CD}^{+}{ }^{+} \mathrm{T}$ cells in the upper chambers of the transwell inserts were cultured either without LMVECs present in the lower chambers or with recombinant TGF- $\beta$ added to the lower chambers to a final concentration of $10 \mathrm{ng} / \mathrm{ml}$. Cultures were incubated for 2 additional days.

Immune TCID $_{\mathbf{5 0}}$ assay. SEOV-infected cell supernatants were titrated by an immune $50 \%$ tissue culture infective dose $\left(\mathrm{TCID}_{50}\right)$ assay as described previously with modifications $(2,64)$. Vero E6 cells were plated in 96-well plates at $4 \times 10^{4}$ cells per well on the day before the assay. The supernatants were diluted in serial 10-fold dilutions in Dulbecco's modified Eagle's medium (DMEM) (Invitrogen) containing 2\% FBS (Lonza). Vero E6 cells were infected with $100 \mu$ l of the diluted supernatants per well in sextuplicate, incubated for 12 days, and fixed with a cold solution of $95 \%$ ethanol-5\% acetic acid. For immunostaining, cells were permeabilized with $0.1 \%$ Triton X-100; blocked with $3 \%$ bovine serum albumin (BSA) (Sigma-Aldrich) in PBS; and incubated with a rat anti-Andes virus (anti-ANDV) N antibody (a kind gift from Andrew Pekosz), which crossreacts with SEOV N (2), diluted in blocking buffer (1:5,000). The cells were washed twice and incubated with a secondary horseradish peroxidase (HRP)-conjugated goat anti-rat antibody diluted in blocking buffer (1:5,000; Jackson ImmunoResearch). SEOV-positive wells were visualized by adding 3,3',5, $5^{\prime}$-tetramethylbenzidine (TMB) substrates (BD Biosciences), and virus titers were calculated using the Reed-Muench formula.

ELISA for TNF- $\alpha$ quantification. Cell culture supernatants were exposed to UV for $3 \mathrm{~min}$ to inactivate virus for processing samples outside a BSL-3 facility (2). TNF- $\alpha$ was measured using enzyme-linked immunosorbent assay (ELISA) kits for rat TNF- $\alpha$ according to the manufacturer's protocol (R\&D Systems).

RNA isolation and quantitative RT-PCR. RNA was isolated using TRIzol (Invitrogen). Reverse transcription was carried out using the SuperScript III First Strand Synthesis System (Invitrogen) with SEOV S gene-specific primers for subsequent SEOV negative-strand RNA quantification or oligo(dT) for subsequent cellular mRNA quantification. For 
the samples in which $18 \mathrm{~S}$ rRNA was measured by real-time PCR, random hexamer was used in the place of oligo(dT). Primers and probes for realtime PCR were either designed using Primer Express 2.0 software (Applied Biosystems) and purchased commercially (Invitrogen or Applied Biosystems) or purchased as predesigned assays (Applied Biosystems). Quantitative real-time (RT) PCR was performed in 96-well optical reaction plates using the StepOnePlus real-time PCR system (Applied Biosystems). For SEOV RNA quantification, absolute RNA copy numbers were calculated by including a set of standards composed of SR-11 S segment in plasmid pWRG7077 ranging from 2 to $2 \times 10^{6}$ copies $/ \mathrm{ml}$ on each plate. For cellular mRNA quantification, serial dilutions of pools of selected samples were run on each plate to generate a standard curve, from which the expression of genes of interest was calculated. For AMs and LMVECs, host gene expression was normalized to that of Gapdh. Because Gapdh is a poor reference gene for $\mathrm{T}$ cell cultures (4), $\mathrm{T}$ cell gene expression was normalized to that of $18 \mathrm{~S}$ rRNA.

Immunofluorescence. AMs were grown on 4-well glass chamber slides (Nalge Nunc International Corp.) at $2 \times 10^{5}$ cells per well. LMVECs were grown on fibronectin-coated $6.5-\mathrm{mm}$ transwell inserts $(0.4-\mu \mathrm{m}$ pore size; Corning Inc.) at $2.5 \times 10^{4}$ cells per transwell insert. AMs and LMVECs were infected with SEOV at an MOI of 0.5 or 5 . At 3 and 6 days after infection, cells were fixed with $4 \%$ paraformaldehyde, permeabilized with $0.1 \%$ Triton X-100, and blocked with $5 \%$ normal goat serum (Thermo Scientific) for $1 \mathrm{~h}$ at room temperature. The cells were incubated with primary rat anti-ANDV N antibody (1:500) diluted in blocking buffer overnight, washed three times with PBS, and incubated for $1 \mathrm{~h}$ with Alexa Fluor 488-conjugated goat anti-rat and Alexa Fluor 594-conjugated goat anti-rabbit secondary antibodies (1:150; Invitrogen) diluted in blocking buffer. Nuclei were counterstained with 4',6-diamidino-2-phenylindole (DAPI) (Sigma). A Nikon Eclipse 90i microscope and Volocity Imaging software (PerkinElmer) were used for image acquisition.

Flow cytometry. Cells were collected and washed in cold fluorescenceactivated cell sorter (FACS) buffer (PBS containing 0.5\% BSA and 0.1\% sodium azide) and blocked with FcR (BD Pharmingen). AMs were incubated with combinations of the following anti-rat antibodies or antibodies that cross-react with rat: MHC-I-phycoerythrin (PE) (clone OX-27; AbD Serotec), MHC-II-peridinin chlorophyll protein (PerCP) (clone OX-6; BD Pharmingen), and CD80-allophycocyanin (APC) (clone 3H5; Invitrogen). LMVECs were incubated with anti-rat MHC-I-PE (clone OX-27; AbD Serotec), MHC-II-PerCP (clone OX-6; BD Pharmingen), and ICAM-1-PE (clone 1A29; AbD Serotec). For the coculture experiments, $\mathrm{T}$ cells were incubated with anti-rat CD4-APC (Clone OX-35; BD Pharmingen). AMs and LMVECs were fixed in $2 \%$ paraformaldehyde for $30 \mathrm{~min}$, which is sufficient for inactivating virus for processing outside a BSL-3 facility (39). AMs were permeabilized with PBS containing $0.1 \%$ Triton X-100. Intracellular CD68 was stained with anti-rat CD68-fluorescein isothiocyanate (FITC) (clone ED1; AbD Serotec) or CD68-PE (clone ED1; AbD Serotec). T cells were fixed and permeabilized using the FoxP3 staining buffer set (eBioscience) according to the manufacturer's protocol and incubated with a FoxP3-FITC antibody (clone FJK-16S; eBioscience). Cells were sorted using a BD FACSCalibur cytometer (BD Biosciences) and the CellQuest Pro software (BD Biosciences). Data were analyzed using FlowJo software (TreeStar Inc., Ashland, OR).

SDS-PAGE and Western blotting. Mock-infected or SEOV-infected LMVECs in 24-well plates were lysed in $100 \mu \mathrm{l} /$ well of M-PER mammalian protein extraction reagent (Thermo Scientific) supplemented with $1 \%$ (vol/vol) protease inhibitor cocktail (Sigma). Cell lysates were separated on $10 \%(\mathrm{wt} / \mathrm{vol}$ ) SDS polyacrylamide gels and electrophoretically blotted onto polyvinylidene difluoride (PVDF) membranes (Invitrogen) according to standard procedures. The membranes were blocked with 5\% nonfat milk for $1 \mathrm{~h}$ at room temperature and treated with rabbit antiPD-L1 (Santa Cruz Biotechnology) diluted in 5\% BSA (1:500) overnight at $4^{\circ} \mathrm{C}$. After washing with phosphate-buffered saline with $0.1 \%$ Tween 20 (T-PBS), the membranes were incubated with an HRP-conjugated goat anti-rabbit secondary antibody (Santa Cruz Biotechnology) in 5\% nonfat milk for $1 \mathrm{~h}$ at room temperature. Specific protein bands were visualized using SuperSignal West Pico Chemiluminescent Substrate and exposed to autoradiography films (Denville Scientific Inc.). For the detection of $\beta$-actin, membranes that had been blotted for PD-L1 were stripped with a stripping buffer $(62.5 \mathrm{mM}$ Tris- $\mathrm{HCl}, \mathrm{pH} 6.8,2 \%$ SDS, and $100 \mathrm{mM}$ $\beta$-mercaptoethanol) for $20 \mathrm{~min}$, blocked with $5 \%$ milk, and reblotted with rabbit anti- $\beta$-actin (Santa Cruz Biotechnology; 1:200) in combination with a horseradish peroxidase-conjugated goat anti-rabbit secondary antibody, following the same procedures as for PD-L1 staining.

Statistical analyses. One-way or two-way analyses of variance (ANOVAs) were used to analyze group differences in quantitative data. Significant interactions were further analyzed using Tukey pairwise comparisons. Comparison of SEOV TCID T0 $_{50}$ data was done by Student $t$ tests. For all statistical tests, mean differences were considered significant if $P$ was $<0.05$.

\section{RESULTS}

SEOV productively infects rat AMs and LMVECs. To investigate whether AMs and LMVECs from rats support SEOV replication, cells were infected with SEOV, and in both cell types, there was a time- and dose-dependent increase in cell-associated negativesense SEOV RNA, in which the largest amount of viral RNA was detected in cells infected with SEOV at an MOI of 5 at 6 days p.i. (Fig. 1A and B) $(P<0.001)$. In SEOV-infected AM cultures, virus antigen ( $\mathrm{N}$ protein)-positive cells were detected and increased over time at all MOIs (from approximately 25\% to 50\% in AMs infected with SEOV at an MOI of 0.5 and from $32 \%$ to $93 \%$ in cells infected with SEOV at an MOI of 5) (Fig. 1C). In SEOV-infected LMVEC cultures, the majority of cells in the infected cultures were virus antigen positive at 3 days (approximately 90\% and 98\% in LMVECs infected with SEOV at an MOI of 0.5 or 5 , respectively) and 6 days p.i. ( $97 \%$ and $98 \%$ in cells infected with SEOV at an MOI of 0.5 or 5 , respectively). (Fig. 1D). Infectious SEOV particles were detected in the supernatants from AMs and LMVECs at 6 days p.i., but not 1 day p.i., with titers being higher in LMVEC than AM cultures (Fig. 1E and F) $(P<0.001)$. These data demonstrate that both rat AMs and LMVECs are susceptible to SEOV infection, the virus can complete its life cycle in these cells, and levels of infection are greater in LMVECs than than in AMs.

SEOV infection does not induce antiviral or proinflammatory responses in either rat AMs or LMVECs. We next examined whether SEOV infection induces innate immune responses in these cell types. Infection at either low or high MOIs with SEOV did not induce the expression of $I f n \beta, C c l 5$, or $C x c l 10$ in AMs (Fig. $2 \mathrm{~A}$ to $\mathrm{C}$ ) or LMVECs (Fig. 2E to G) or the secretion of TNF- $\alpha$ by AMs (Fig. 2D). In contrast, both AMs and LMVECs expressed high levels of proinflammatory and antiviral cytokines and chemokines in response to inflammatory stimuli, including IFN- $\gamma$, LPS, or pIC treatment $(P<0.001$ in each case), indicating that these cells are capable of mounting proinflammatory and antiviral responses but that SEOV infection does not trigger these responses in either cell type.

SEOV infection induces $T g f \beta$ expression but does not alter other T cell-related markers in rat AMs. To determine whether SEOV infection alters the ability of rat AMs to induce T cell activation, the expression of $\mathrm{T}$ cell activation-related factors was measured at 1, 3, and 6 days p.i. with SEOV at low and high MOIs and compared with mock-infected cells and cells treated with inflammatory stimuli. In AMs, SEOV infection at an MOI of 0.5 significantly induced the expression of Tgf $\beta$ by 6 days p.i. (Fig. 3A) $(P=$ $0.005)$, whereas stimulation with LPS/IFN- $\gamma$ downregulated $T g f \beta$ 

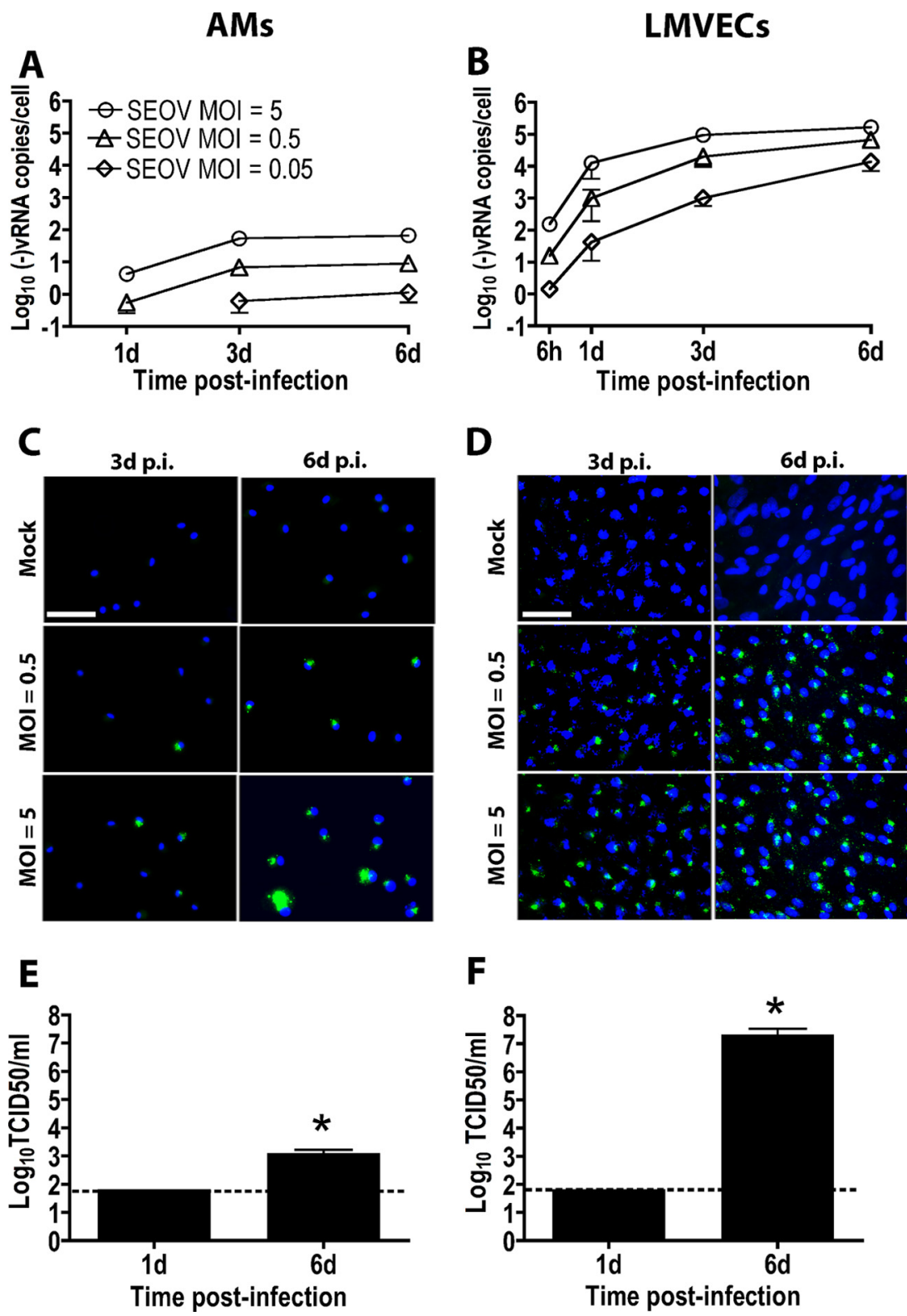

FIG 1 SEOV productively infects AMs and LMVECs from Norway rats. AMs and LMVECs were inoculated with medium alone or with medium containing SEOV. Cells and supernatants were collected at the indicated time points. (A and B) Cell-associated negative-sense SEOV RNA in AMs (A) and LMVECs (B) was quantified by real-time PCR. The data are expressed as means \pm standard errors of the mean (SEM) of three independent experiments. $d$, days. (C and D) SEOV N protein in AMs (C) and LMVECs (D) was identified with an antibody that cross-reacts with SEOV N protein (green), and cell nuclei were counterstained with DAPI (blue). The images were acquired using a $40 \times$ objective lens. Bars, $50 \mu \mathrm{m}$. (E and F) At 1 and 6 days p.i., supernatants from AMs (E) and LMVECs (F) infected with SEOV at an MOI of 5 were collected, and infectious-virus titers were quantified using an immune $\mathrm{TCID}_{50}$ assay. The dashed lines represent the lower limit of detection of the assay. The data are expressed as means and SEM of three independent experiments. The asterisks indicate significant differences relative to day 1 SEOV TCID ${ }_{50}$ titers; $P<0.001$; Student's $t$ test.

expression 3 days p.i. (Fig. 3A) $(P=0.024)$ compared with mocktreated cells. The surface expression of MHC-II on SEOV-infected AMs was comparable to that on mock-infected cells and was significantly lower than the expression on cells treated with inflammatory stimuli (Fig. 3B) $(P<0.05$ in each case). The surface expression of MHC-I was not induced by either SEOV infection or LPS/IFN- $\gamma$ stimulation in AMs (Fig. 3C). The surface expression of the costimulatory molecule CD80 on SEOV-infected AMs was also comparable to that of mock-infected cells and was significantly lower than the expression on cells treated with inflamma- tory stimuli at 3 days p.i. but significantly higher than the expression on cells treated with inflammatory stimuli at 6 days p.i. (Fig. 3D) $(P<0.05)$.

SEOV infection does not increase the ability of rat AMs to induce Treg activity. To determine whether SEOV infection of rat AMs upregulates Treg activity, AMs were mock infected or infected with SEOV at an MOI of 0.5 or 5 for $24 \mathrm{~h}$ and then cocultured with allogeneic $\mathrm{CD} 4{ }^{+} \mathrm{T}$ cells for 4 days. Allogeneic $\mathrm{CD} 4{ }^{+} \mathrm{T}$ cells cocultured with mock-infected AMs significantly upregulated Foxp3 expression compared with $\mathrm{CD}^{+}{ }^{+} \mathrm{T}$ cells incubated 
A

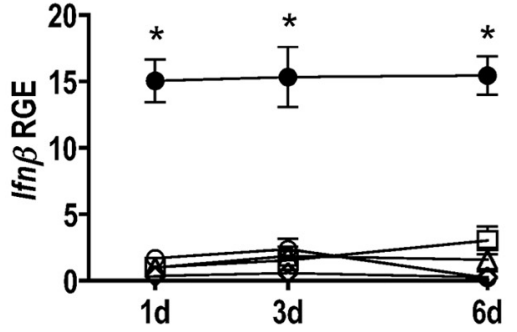

B

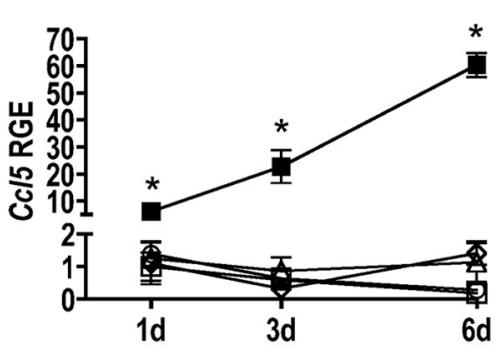

C
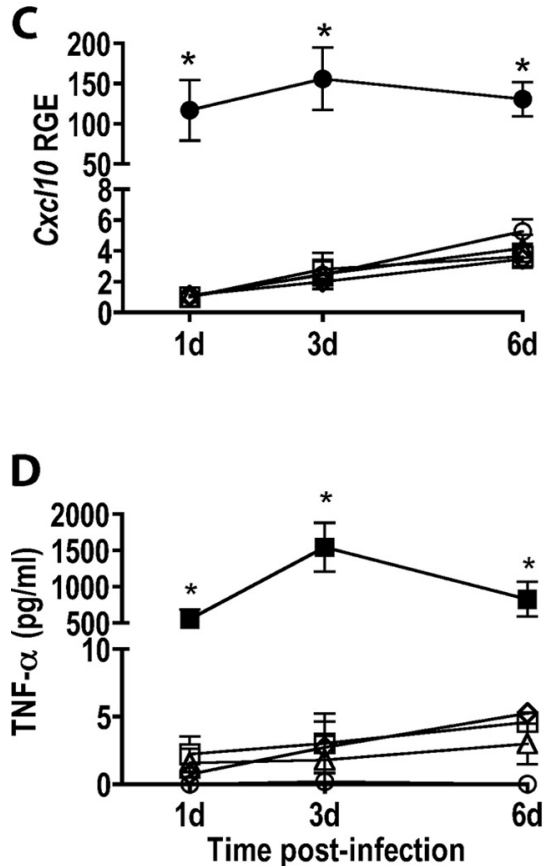

E

LMVECS
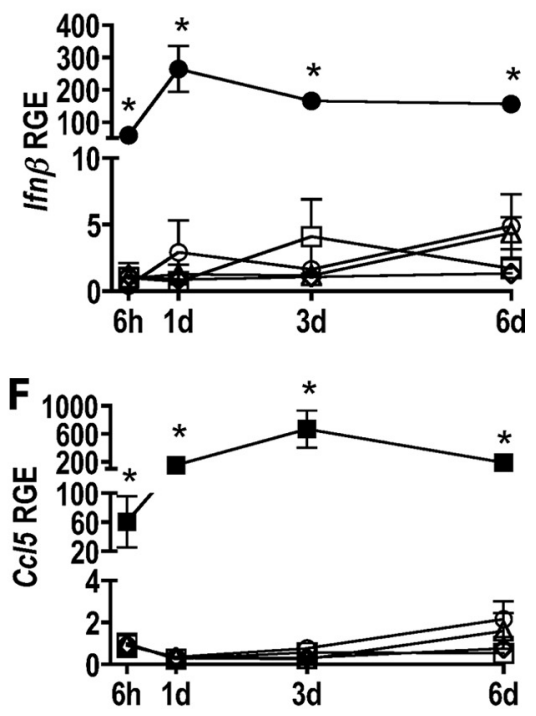

G

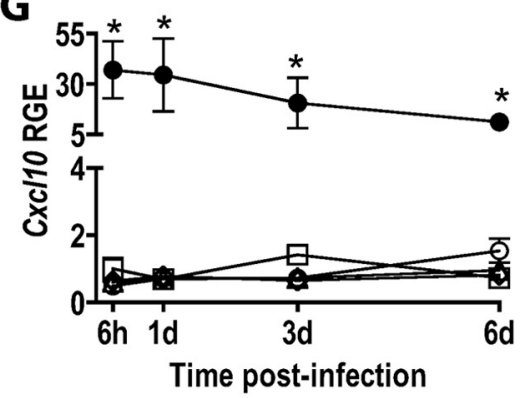

FIG 2 SEOV infection does not induce antiviral or proinflammatory responses in AMs or LMVECs. AMs and LMVECs were inoculated with medium alone or medium containing SEOV. The positive controls included cells stimulated with pIC, LPS in combination with IFN- $\gamma$ (AMs), or LPS (LMVECs) for $24 \mathrm{~h}$ prior to sample collection. Ifn $\beta, C c l 5$, and Cxcl10 mRNA expression in AMs (A, B, and C) and LMVECs (E, F, and G) was quantified by real-time PCR and is expressed as relative gene expression (RGE) compared to mock-infected cells at 1 day (AMs) or 6 h (LMVECs). (D) TNF- $\alpha$ concentrations in AM supernatants were measured by ELISA. All data are expressed as means \pm SEM of three independent experiments. The asterisks indicate significant differences relative to mock-infected cells at the corresponding time point; $P<0.05 ; 2$-way ANOVAs.

alone (Fig. 4A) $(P=0.031)$, which was mitigated in T cells cocultured with SEOV-infected cells. To evaluate whether AMs induce other subsets of $\mathrm{CD} 4^{+} \mathrm{T}$ cells, the expression of genes associated with Th1, Th2, and Th17 cells was examined. The expression of Il17, Tbet, If $n \gamma$, Il4, and Illo was not altered in $\mathrm{CD}^{+}{ }^{+} \mathrm{T}$ cells cultured with either SEOV-infected or uninfected AMs, which were each significantly lower than the expression of these genes in $\mathrm{CD}^{+}{ }^{+}$T cells stimulated with anti-CD3/CD28 (Fig. 4B to F) $(P<$
0.001 in each case). FoxP3 ${ }^{+}$Treg cell frequencies were significantly increased in $\mathrm{CD}^{+}{ }^{+} \mathrm{T}$ cells cocultured with AMs, regardless of infection status, compared to $\mathrm{CD} 4{ }^{+} \mathrm{T}$ cells cultured alone (Fig. $4 \mathrm{G}$ and $\mathrm{H})(P<0.001)$. AMs, in general, enhance frequencies of Treg cells in culture irrespective of SEOV infection.

SEOV infection selectively induces PD-L1 in rat LMVECs. To determine whether SEOV infection alters the ability of rat LMVECs to present antigen and activate T cells, T cell-related 

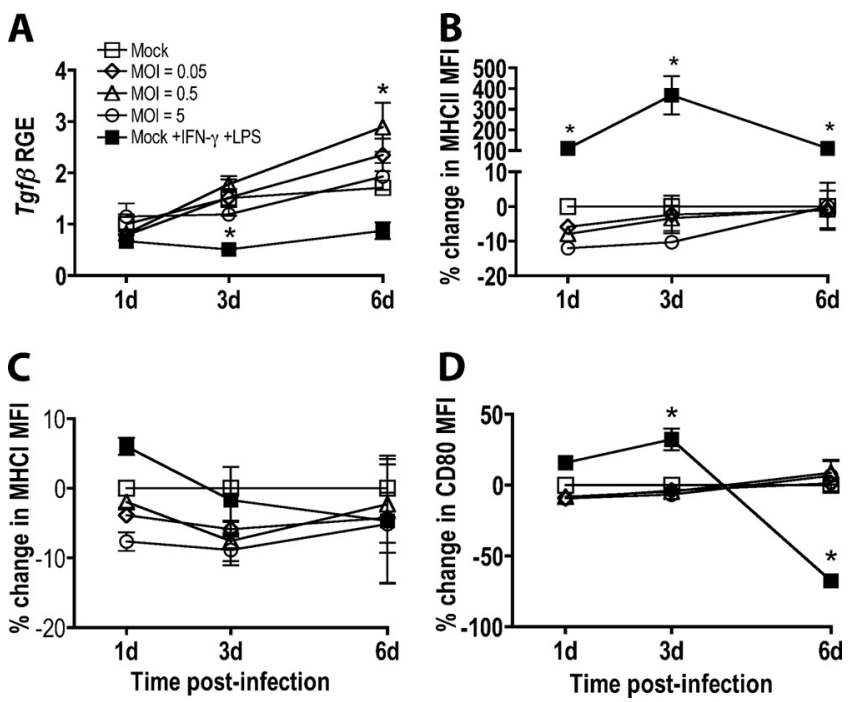

FIG 3 SEOV infection induces Tgf $\beta$, but not other T cell-related marker expression, in AMs. AMs were inoculated with medium alone or medium containing SEOV. Controls included AMs stimulated with a combination of recombinant IFN- $\gamma$ and LPS for $24 \mathrm{~h}$ prior to sample collection. (A) Tg $\beta$ expression in AMs was quantified by real-time PCR and is expressed as RGE compared to mock-infected cells at 1 day. (B, C, and D) Cell surface MHC-II, MHC-I, and CD80 expression was quantified by flow cytometry and expressed as percent changes in median fluorescence intensity (MFI) compared to mockinfected cells at the corresponding time point. All data are expressed as means \pm SEM of three independent experiments. The asterisks indicate significant differences relative to mock-infected cells at the corresponding time points; $P<0.05 ; 2$-way ANOVAs. factors, with particular attention devoted to the factors associated with endothelial cell induction of Treg cells (i.e., ICAM-1 and PD-L1) (41), were measured at 1, 3, and 6 days p.i. with SEOV at low and high MOIs and compared with mock-infected cells and cells treated with inflammatory stimuli. SEOV infection did not induce Tgf $\beta$ expression in rat LMVECs at any MOI, nor did IFN- $\gamma$ stimulation alter Tgf $\beta$ expression in rat LMVECs (Fig. 5A). The surface expression of MHC-II, MHC-I, and ICAM-1 on SEOV-infected LMVECs was comparable to that on mock-infected cells and was significantly lower than the expression on cells treated with inflammatory stimuli (Fig. 5B to $\mathrm{D})(P<0.05$ in each case). SEOV infection induced a dosedependent increase in PD-L1 protein expression in LMVECs compared with mock-infected cells (Fig. 5E).

SEOV-infected rat LMVECs induce Treg cell activity. To determine whether SEOV infection of rat LMVECs upregulates Treg cell activity, LMVECs were mock infected or infected with SEOV at an MOI of 0.5 or 5 for $24 \mathrm{~h}$ and then cocultured with allogeneic $\mathrm{CD} 4{ }^{+} \mathrm{T}$ cells for 4 days. Coculture of allogeneic $\mathrm{CD} 4^{+} \mathrm{T}$ cells with SEOV-infected LMVECs significantly increased the expression of Foxp3 compared with $\mathrm{CD} 4{ }^{+} \mathrm{T}$ cells cultured alone or with mockinfected LMVECs (Fig. 6A) $(P<0.05)$. Conversely, the expression of genes associated with Th17, Th1, and Th2 activity was not altered in $\mathrm{CD}^{+}{ }^{+} \mathrm{T}$ cells cultured with either SEOV-infected or uninfected LMVECs and was significantly lower than the expression of these genes in $\mathrm{CD}^{+} \mathrm{T}$ cells stimulated with anti-CD3/CD28 (Fig. 6B to F) $\left(P<0.001\right.$ in each case). Allogeneic $\mathrm{CD}^{+} \mathrm{T}$ cells
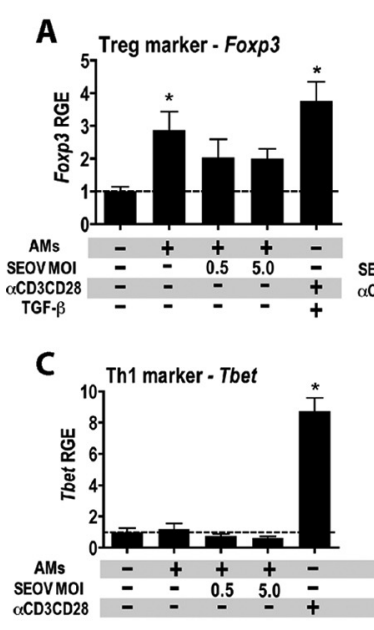

D Th1 marker - Ifn $\gamma$
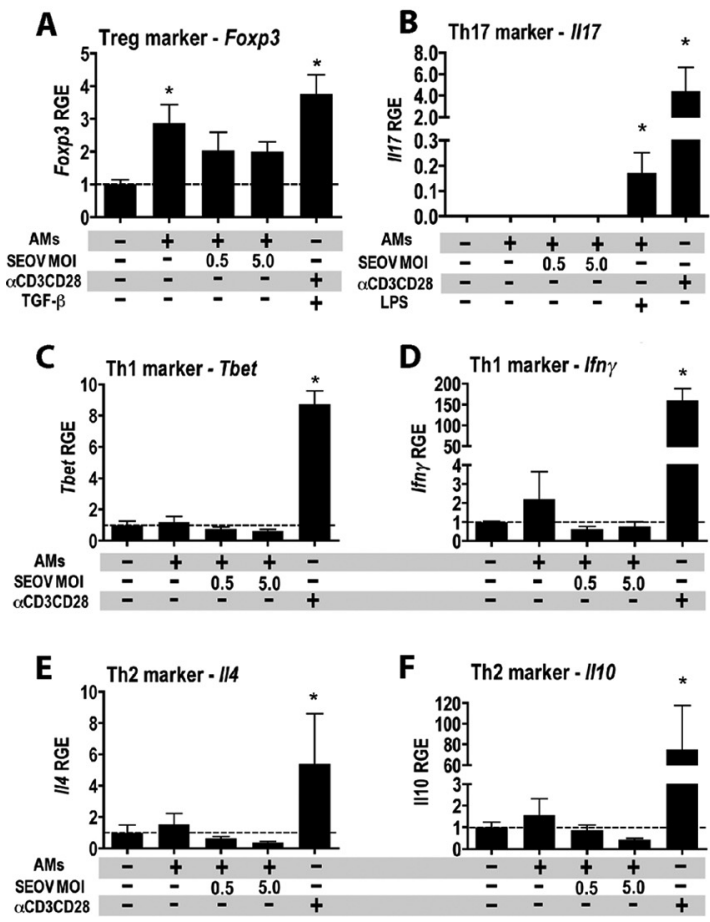

\section{F}

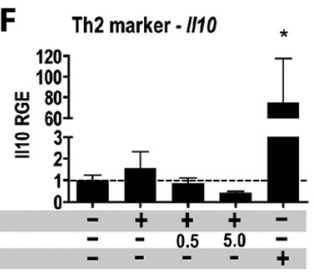

G
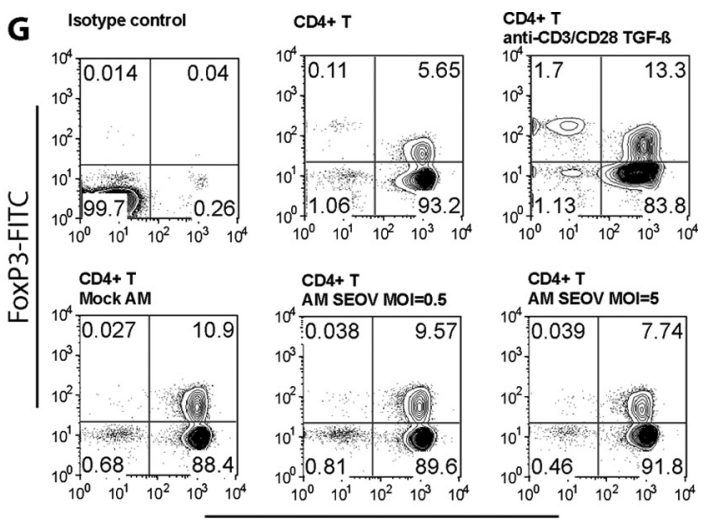

CD4-APC

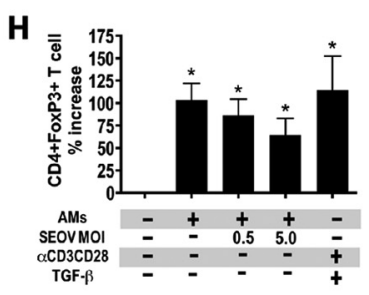

FIG 4 AMs induce a Treg cell phenotype in allogeneic $\mathrm{CD} 4^{+} \mathrm{T}$ cells regardless of infection status. (A to F) AMs from Lewis rats were inoculated with medium alone or with medium containing SEOV. At 1 day p.i., splenic $\mathrm{CD} 4^{+} \mathrm{T}$ cells from Brown Norway rats were added to AM cultures at a AM/T cell ratio of 1:10. After 4 days of coculture, nonadherent cells were collected, and the expression of Foxp3, Il17, Tbet, Ifn $\gamma$, Il4, and Il10 was quantified by real-time PCR and is expressed as RGE compared to $\mathrm{CD} 4^{+} \mathrm{T}$ cells cultured alone. The dashed lines represent the gene expression level of $\mathrm{CD} 4^{+} \mathrm{T}$ cells cultured alone. Data are expressed as means and SEM from three independent experiments. (G) The frequency of CD4 ${ }^{+}$FoxP3 ${ }^{+}$Treg cells among the cocultured cells was analyzed by flow cytometry. (H) The percent change in Treg cell frequencies among $\mathrm{CD} 4^{+} \mathrm{T}$ cells cultured with AMs relative to $\mathrm{CD} 4^{+} \mathrm{T}$ cells cultured alone from three independent experiments is expressed as means and SEM. The asterisks indicate significant differences relative to $\mathrm{CD} 4^{+} \mathrm{T}$ cells cultured alone; $P<0.05$; one-way ANOVA. 
A

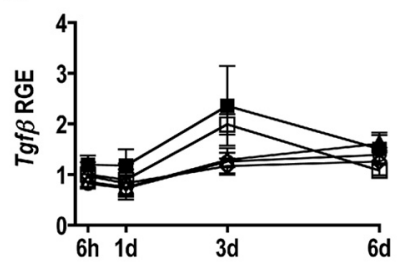

C

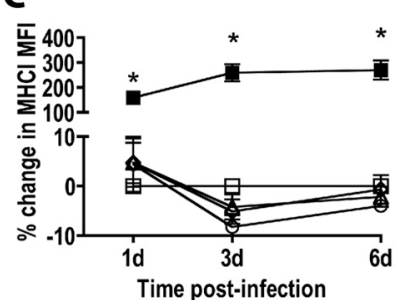

E

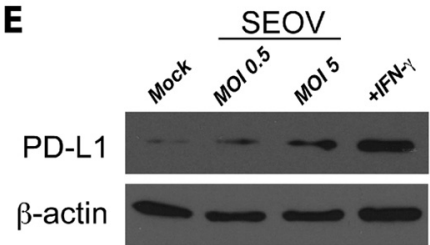

B

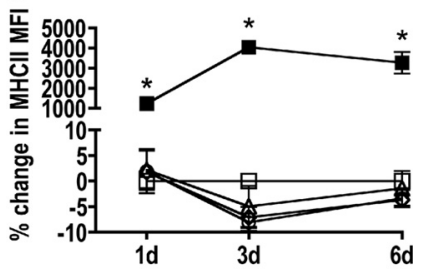

D

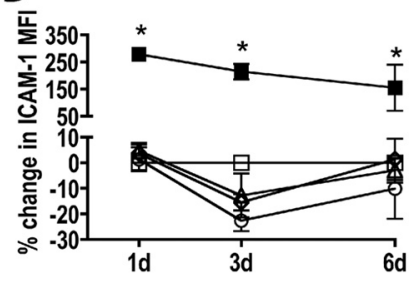

FIG 5 SEOV infection induces total PD-L1 protein expression but does not alter the expression of other T cell activation markers in rat LMVECs. LMVECs were inoculated with medium alone or medium containing SEOV. Controls included LMVECs stimulated with IFN- $\gamma$ for $24 \mathrm{~h}$ prior to sample collection. (A) Tgf $\beta$ expression in LMVECs was quantified by real-time PCR and is expressed as RGE compared to mock-infected cells at $6 \mathrm{~h}$. (B, C, and D) Cell surface MHC-II, MHC-I, and ICAM-1 expression was quantified by flow cytometry and expressed as percent changes in MFI compared to mock-infected cells at the corresponding time point. All data are expressed as means \pm SEM of three independent experiments. The asterisks indicate significant differences relative to mock-infected cells at the corresponding time points; $P<$ 0.05; 2-way ANOVAs. (E) PD-L1 expression was measured in mock-infected, SEOV-infected, and IFN- $\gamma$-treated LMVECs that were lysed at 3 days p.i., and PD-L1 and $\beta$-actin expression in cell lysates was detected by Western blotting. The data are representative of three independent experiments.

cocultured with SEOV-infected LMVECs had significantly higher FoxP3 $^{+}$Treg cell frequencies than $\mathrm{CD} 4^{+} \mathrm{T}$ cells cultured alone or with mock-infected LMVECs (Fig. 6G and H) $(P<0.001)$.

The induction of Treg cells by SEOV-infected rat LMVECs is dependent on virus replication and cell contact. To determine whether Treg cell induction by SEOV-infected LMVECs is stimulated by viral particles alone or is dependent on virus replication, LMVECs were mock infected, infected with SEOV at an MOI of 5, or infected with UV-inactivated SEOV at an MOI of 5 for $24 \mathrm{~h}$ and cocultured with allogeneic $\mathrm{CD} 4^{+} \mathrm{T}$ cells for 4 days. Allogeneic $\mathrm{CD}^{+}{ }^{+} \mathrm{T}$ cells cocultured with SEOV-infected LMVECs showed greater expression of Foxp 3 and FoxP $3^{+}$Treg cell frequencies than $\mathrm{CD} 4{ }^{+} \mathrm{T}$ cells cultured alone or with mock-infected LMVECs (Fig. $7 \mathrm{~A}$ and $\mathrm{B})\left(P<0.01\right.$ in each case). In contrast, allogeneic CD $4^{+} \mathrm{T}$ cells cultured with UV-inactivated SEOV-infected LMVECs had levels of Foxp3 expression and FoxP3 ${ }^{+}$Treg cell frequencies that were comparable to those of $\mathrm{CD} 4^{+} \mathrm{T}$ cells cultured alone or with mock-infected LMVECs (Fig. 7A and B).

To determine if increased expression of PD-L1 on SEOV-infected LMVECs contributes to the induction of Treg cells, we

sought to neutralize PD-L1 on the surfaces of SEOV-infected LMVECs. The commercially available anti-rat PD-L1 antibody did not bind to undenatured PD-L1 on the surfaces of live LMVECs (data not shown), indicating that the available antibody would not work as a neutralizing antibody for directly testing whether upregulation of PD-L1 on SEOV-infected LMVECs induces Treg cells. We instead designed experiments to determine whether the induction of Treg cells by SEOV-infected LMVECs is cell contact dependent or attributed to a soluble factor(s) secreted by SEOV-infected LMVECs. Allogeneic $\mathrm{CD}^{+}{ }^{+} \mathrm{T}$ cells were stimulated prior to culture in transwell upper chambers with mock or SEOV-infected (MOI, 5) LMVECs in the lower chambers to eliminate contact between $\mathrm{CD} 4^{+} \mathrm{T}$ cells and LMVECs. Coculture of stimulated allogeneic CD $4^{+}$T cells with SEOV-infected LMVECs in transwells did not increase the expression of Foxp3 compared with stimulated $\mathrm{CD} 4^{+} \mathrm{T}$ cells cultured alone or with mock-infected LMVECs in transwells, all of which were significantly lower than the Foxp 3 expression of stimulated $\mathrm{CD}^{+}{ }^{+} \mathrm{T}$ cells cultured in transwell inserts with TGF- $\beta$ added to the lower chambers (Fig. 7C) $(P<0.001)$. Stimulated allogeneic $\mathrm{CD} 4^{+} \mathrm{T}$ cells cocultured with SEOV-infected LMVECs or mock-infected LMVECs in transwells also had comparable FoxP3 ${ }^{+}$Treg cell frequencies, which were all significantly lower than Treg cell frequencies of stimulated $\mathrm{CD} 4^{+} \mathrm{T}$ cells cultured with TGF- $\beta$ in the lower chambers (Fig. 7D) $(P<0.001)$. These data indicate that induction of Treg cells by SEOV-infected LMVECs is virus replication and cell contact dependent.

\section{DISCUSSION}

Hantaviruses infect macrophages and endothelial cells in both reservoir hosts and humans $(11,43,53,78)$. The severity of hantaviral diseases in humans (i.e., HFRS and HCPS) is partially mediated by increased endothelium permeability $(53,58,73)$. In contrast, reservoir hosts infected with species-specific hantaviruses exhibit no overt pathological disease, which is attributed to virusinduced upregulation of regulatory responses and inhibition of proinflammatory responses $(17-19,68)$; how this occurs, however, has remained elusive. The data from the present study illustrate that both AMs and endothelial cells from a rodent reservoir support hantavirus replication and contribute to the induction of an environment that polarizes $\mathrm{CD} 4{ }^{+} \mathrm{T}$ cell differentiation toward a Treg cell phenotype.

In SEOV-infected Norway rats, the lungs, more than any other organ examined (e.g., spleen or kidney), support elevated viral replication and regulatory responses, including $T g f \beta$ expression during the acute phase of infection followed by upregulation of Treg cell activity during the persistent phase of infection (17-19). SEOV antigen is localized to AMs and lung endothelial cells of infected rats (18). We have previously shown that rat BMDMs and BM-derived DCs support SEOV replication, with macrophages supporting significantly greater levels of SEOV replication than DCs (2). SEOV infection does not trigger antiviral or proinflammatory responses but suppresses the ability of these BM-derived APCs to respond appropriately to inflammatory stimuli (2). Embryonic fibroblasts from bank voles also do not increase If $n \beta$ or Mx2 mRNA expression when infected with the species-specific hantavirus Puumala virus (PUUV) (70). In contrast to reservoir host-derived cells, pathogenic hantavirus infection of human endothelial cells or DCs induces antiviral cytokine (i.e., Ifn $\beta$ ) and chemokine (i.e., Ccl5 and $\mathrm{Cxcl10}$ ) expression and increases cell 
A

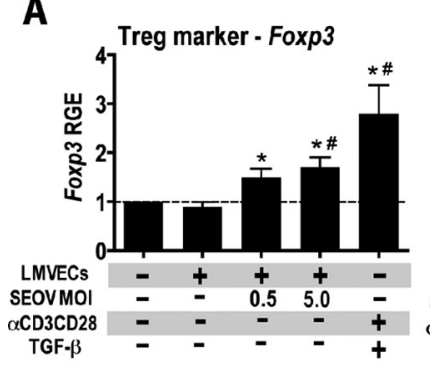

B

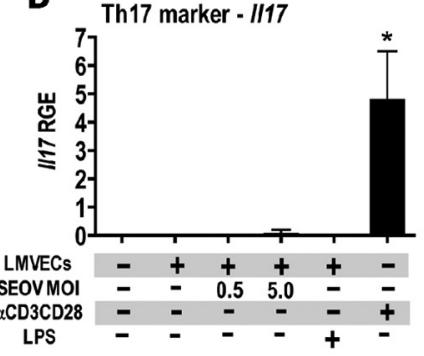

G

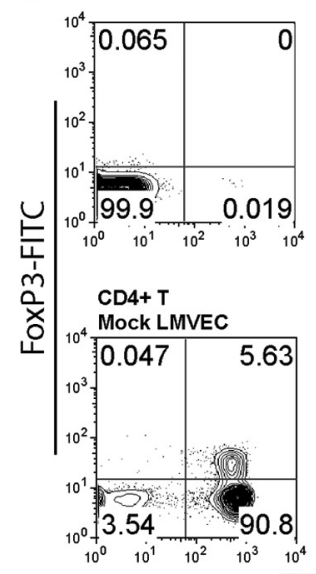

CD4+ T

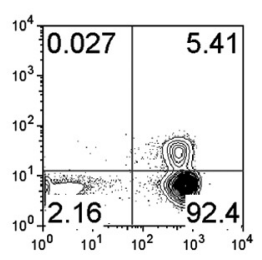
anti-CD3/CD28 TGF-ß

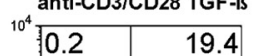

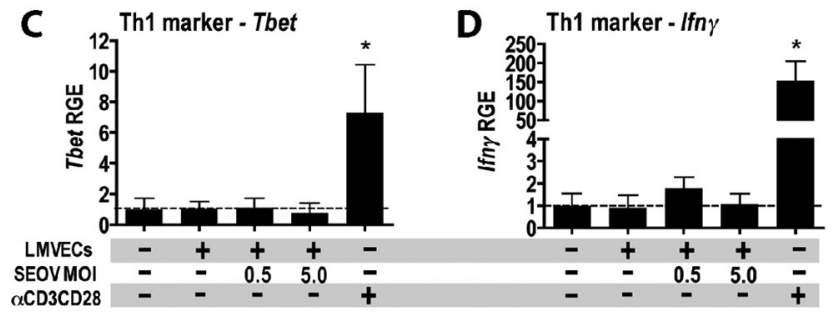

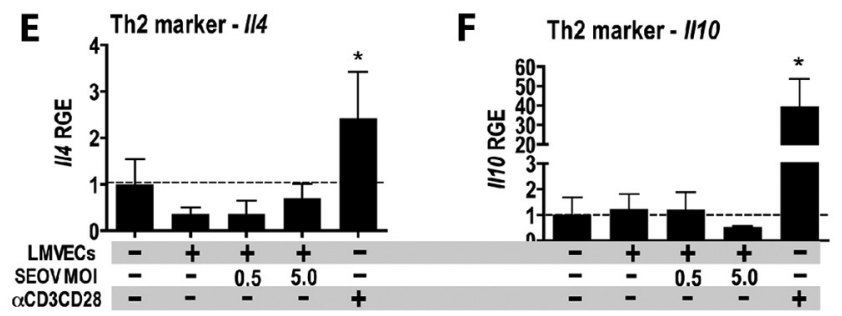

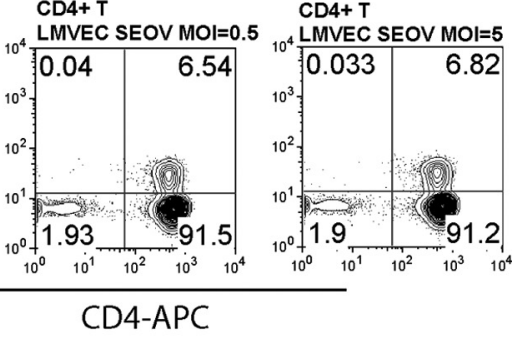

H

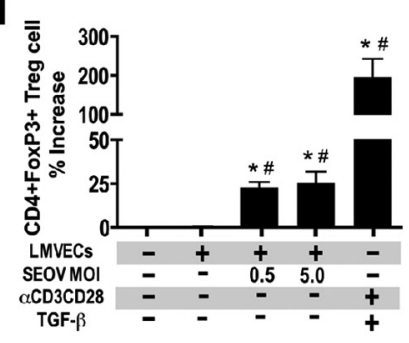

FIG 6 SEOV infection of LMVECs increases Foxp3 expression and Treg cell frequency in allogeneic CD4 ${ }^{+}$T cells. (A to F) LMVECs from Sprague-Dawley rats were inoculated with medium alone or with medium containing SEOV. At 1 day p.i., splenic CD4 ${ }^{+} \mathrm{T}$ cells from Brown Norway rats were added to LMVEC cultures at a LMVEC/T cell ratio of 1:10. After 4 days of coculture, nonadherent cells were collected, and the expression of Foxp3, Ill7, Tbet, If $n \gamma$, Il4, and Il10 was quantified by real-time PCR and is expressed as RGE compared to CD4 ${ }^{+}$T cells cultured alone. The data are expressed as means and SEM from three independent experiments. The dashed lines represent the gene expression level of $\mathrm{CD} 4^{+} \mathrm{T}$ cells cultured alone. $(\mathrm{G})$ The frequency of $\mathrm{CD} 4^{+}$FoxP $3^{+}$Treg cells among the cocultured cells was analyzed by flow cytometry. $(\mathrm{H})$ The percentage change in Treg cell frequencies among CD $4^{+}$T cells cultured with LMVECs relative to CD4 ${ }^{+}$ $\mathrm{T}$ cells cultured alone from three independent experiments are expressed as means and SEM. ${ }^{*}$, significant difference relative to CD ${ }^{+}$T cells cultured alone; \#, significant difference relative to $\mathrm{CD} 4^{+} \mathrm{T}$ cells cocultured with mock-infected LMVECs; $P<0.05$; one-way ANOVA.

surface activation markers (i.e., MHC-I and ICAM-1) that contribute to the enhanced proinflammatory response and $\mathrm{CD} 8^{+} \mathrm{T}$ cell activity in HFRS and HCPS patients (30, 40, 62, 71). Collectively, these studies suggest that hantaviruses have evolved mechanisms to evade innate immune surveillance in their reservoir hosts, but not in humans, at a cellular level.

Rat AMs and, to a greater extent, LMVECs play fundamental roles in supporting SEOV replication, with the virus completing its life cycle in both cell types. SEOV infection of rat LMVECs results in greater production of virus than with AMs or even Vero E6 cells (data not shown), a type I IFN-deficient cell line that is traditionally used to propagate hantaviruses $(20,36,60)$. These data suggest that both rat AMs and LMVECs contribute to SEOV persistence in vivo. How hantaviruses replicate in reservoir host cells without inducing cellular immune responses that promote virus clearance has remained unspecified.

SEOV infection of rat AMs and LMVECs creates an environment that polarizes $\mathrm{CD} 4^{+} \mathrm{T}$ cell differentiation toward a Treg cell phenotype and provides one mechanism by which hantaviruses escape clearance and cause persistent infections in rodent reservoirs. The absence of innate proinflammatory cytokine and chemokine responses in rat AMs or LMVECs following SEOV infection minimizes the induction of Th1, Th2, and Th17 cells and shifts the $\mathrm{CD} 4^{+} \mathrm{T}$ cell population in the lungs toward a regulatory phenotype. In the lungs of SEOV-infected rats, the frequency of Treg cells significantly increases after the SEOV RNA load peaks during the acute phase of infection, suggesting the induction of Treg cells during the persistent phase of infection might be dependent on SEOV replication in cells, including AMs and lung endothelial cells, during the acute phase of infection (19). Macrophages and endothelial cells can induce $\mathrm{CD} 4^{+} \mathrm{T}$ cells into Treg cells following appropriate cell (e.g., MHC-II engagement and costimulation and PD-1-PD-L1 pathway activation) or cytokine (e.g.) presence of TGF- $\beta$ ) stimulation $(38,41,72)$. Coculturing of naïve $\mathrm{CD} 4^{+} \mathrm{T}$ cells with infected LMVECs induced $\mathrm{CD} 4^{+} \mathrm{T}$ cells to differentiate into Treg cells. SEOV-infected LMVECs induced an approximately $25 \%$ increase in Treg cell frequency in $\mathrm{CD} 4^{+} \mathrm{T}$ cell cultures, which is comparable in magnitude to the increase observed in SEOV-infected rats (19), as well as in other virus-host cell systems $(12,79,80)$. The induction of Treg cells by SEOV-infected LMVECs is dependent on virus replication and not merely on the presence of virus particles. These data suggest that hantavirus replication in LMVECs contributes to the increased Treg frequency in the lungs of infected rats (19) and possibly increases Foxp 3 expression in T cells from persistently Sin Nombre virus-infected deer mice (68).

Treg cell induction by endothelial cells is PD-L1 dependent $(41,72)$. SEOV infection of LMVECs increased PD-L1 protein 
A

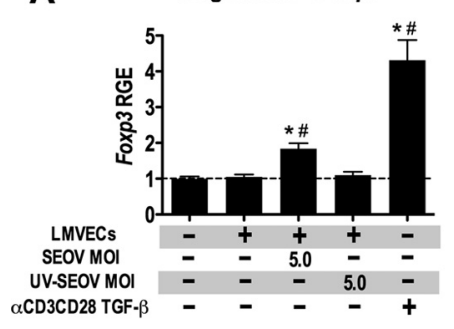

C

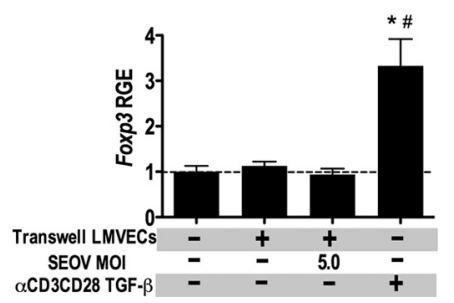

B Treg \% increase

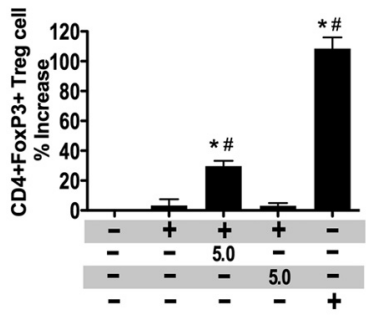

D

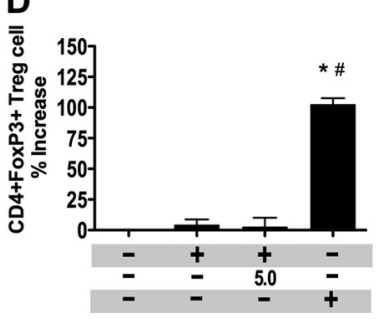

FIG 7 Induction of Treg cells in allogeneic $\mathrm{CD} 4^{+} \mathrm{T}$ cell cultures by SEOVinfected LMVECs requires SEOV replication and cell contact. (A) LMVECs from Sprague-Dawley rats were inoculated with medium alone, medium containing SEOV, or medium containing UV-inactivated SEOV. At 1 day p.i., splenic $\mathrm{CD} 4^{+} \mathrm{T}$ cells from Brown Norway rats were added to LMVEC cultures at a LMVEC/T cell ratio of 1:10. After 4 days of coculture, nonadherent cells were collected, and the expression of Foxp 3 was quantified by real-time PCR and is expressed as RGE compared to $\mathrm{CD} 4^{+} \mathrm{T}$ cells cultured alone. The data are expressed as means and SEM from three independent experiments. (B) The frequency of $\mathrm{CD} 4^{+} \mathrm{FoxP}^{+}$Treg cells among the cocultured cells was analyzed by flow cytometry. The percent change in Treg cell frequencies among $\mathrm{CD} 4^{+} \mathrm{T}$ cells cultured with LMVECs relative to $\mathrm{CD} 4^{+} \mathrm{T}$ cells cultured alone from three independent experiments is expressed as means and SEM. (C) For transwell coculture experiments, LMVECs from Sprague-Dawley rats were cultured in the bottom chambers of transwells and inoculated with medium alone or with medium containing SEOV. Splenic CD4 ${ }^{+} \mathrm{T}$ cells from Brown Norway rats were stimulated with a combination of plate-bound anti-CD3 and soluble anti-CD28. At 3 days p.i., stimulated $\mathrm{CD}^{+} \mathrm{T}$ cells were added to the upper chambers of the transwells to eliminate LMVEC-CD4 ${ }^{+} \mathrm{T}$ cell contact. After 2 days of coculture, $\mathrm{CD} 4^{+} \mathrm{T}$ cells in the upper chambers were collected, and the expression of Foxp 3 was quantified by real-time PCR and expressed as RGE compared to $\mathrm{CD}^{+} \mathrm{T}$ cells cultured alone in the upper chambers without LMVECs in the lower chamber. The data are expressed as means and SEM from three independent experiments. (D) The frequency of $\mathrm{CD}^{+}{ }^{+} \mathrm{FoxP}^{+}$ Treg cells among the $\mathrm{CD} 4^{+} \mathrm{T}$ cells in the upper chamber was analyzed by flow cytometry. The percent change in Treg cell frequencies relative to $\mathrm{CD} 4^{+} \mathrm{T}$ cells cultured alone from three independent experiments is expressed as means and SEM. ${ }^{*}$, significant difference relative to $\mathrm{CD}^{+}{ }^{+} \mathrm{T}$ cells cultured alone; \#, significant difference relative to $\mathrm{CD} 4^{+} \mathrm{T}$ cells cocultured with mock-infected LMVECs; $P<0.05$; one-way ANOVA. The dashed lines represent the gene expression level of $\mathrm{CD} 4^{+} \mathrm{T}$ cells cultured alone.

expression. PD-L1 alone (i.e., PD-L1-coated beads) can induce Treg cells in vitro (22). The cell contact dependence of Treg cell induction by SEOV-infected LMVECs indicates that Treg cell induction is mediated by a LMVEC surface protein(s) rather than a LMVEC-secreted soluble factor(s). Taken together, our data suggest that PD-L1 might be one mediator of increased Treg cell activity and the absence of endothelium damage in reservoir hosts infected with species-specific hantaviruses.

The PD-1-PD-L1 pathway regulates the balance between stimulatory and inhibitory signals to maintain peripheral tolerance (23). PD-1 is expressed by activated lymphocytes and myeloid cells, and PD-L1 is expressed by IFN- $\gamma$-stimulated APCs and nonlymphoid cells in many tissues, such as the heart, lung, liver, and spleen $(23,32,50)$. The engagement of PD-1 with PD-L1 inhibits lymphocyte proliferation and cytokine secretion (23). Because of its inhibitory properties, the PD-1-PD-L1 pathway is exploited by many viruses to achieve chronic infection $(50,51)$. For example, activation of the $\mathrm{PD}-1-\mathrm{PD}-\mathrm{L} 1$ pathway plays an important role in chronic lymphocytic choriomeningitis virus, human immunodeficiency virus (HIV), hepatitis B virus, and HCV infections $(3,6-8$, $46,50,57,61,75)$. Whether the enhancement of PL-L1 in SEOVinfected endothelial cells is a significant factor in hantavirus persistence in vivo requires consideration. Our data suggest that the increased endothelial PD-L1 level during SEOV infection might mediate both the induction of Treg cells and possibly the inhibition of $\mathrm{CD} 8^{+} \mathrm{T}$ cell activity to cause persistent infection in reservoir hosts. It is, however, possible that other proteins in addition to $\mathrm{PD}-\mathrm{L} 1$ are involved.

AMs appear to play a supportive role in the maintenance of SEOV replication and induction of an anti-inflammatory pulmonary environment. Although SEOV-infected rat AMs do not increase Treg cell frequency in $\mathrm{CD}_{4}^{+} \mathrm{T}$ cell cultures, these cells might be the cellular source of the early increase in $T g f \beta$ expression in the lungs of SEOV-infected rats (18). AMs play a critical role at the interface between detection of foreign antigens, induction of immune responses, and clearance of pathogens from the lungs $(16,21,42)$. AMs have evolved the ability to clear foreign antigens without extensive activation of inflammatory responses (77). The relatively long half-life (30 days) of AMs and their restrained response to infection make them an ideal niche for pathogens, such as HIV and Mycobacterium tuberculosis, that cause persistent infections in humans $(28,52,54,66)$. We hypothesize that hantaviruses may have evolved mechanisms to exploit AMs, as these cells support productive SEOV replication and are able to induce Treg cells, regardless of their infection status. SEOV-infected AMs caused a slightly mitigated induction of Treg cells that is likely attributable to SEOV-induced inhibition of MHC-II expression on APCs (2).

The goal of the current study was to investigate the possible mechanism(s) underlying the increase in Treg cell frequencies in the lungs of SEOV-infected rats (19) using an in vitro approach, because identifying cell-specific induction of Treg cells in rat lungs is currently not feasible. To achieve this goal, a mixed lymphocyte reaction assay was used to determine whether infected AMs, LMVECs, or both cell types could induce naïve T cells toward a Treg phenotype (i.e., expression of FoxP3). Although using SEOV-specific T cells might be more physiologically relevant, isolation of SEOV-specific T cells from infected rats would not serve the purpose of the current study, which was to establish the cell type involved in the induction of Treg cells from a naïve $\mathrm{CD} 4^{+} \mathrm{T}$ cell population. Allogeneic $\mathrm{T}$ cell cocultures have been used previously to systematically evaluate APC induction of T cell responses during virus infection $(55,56,76)$. This mixed lymphocyte reaction or allogeneic $\mathrm{T}$ cell coculture system also has been used to study the induction of Treg cells by activated murine vascular endothelial cells (41) and human endothelial cells (72). The allogeneic coculture system enabled identification of SEOV-infected endothelial cells as a cell type responsible for Treg cell induction in rats. A limitation of the current study is that, using the allogeneic coculture system as a surrogate, it is not clear whether the induced Treg cells are SEOV specific; determining this remains a goal of future studies.

Hantavirus infection and replication in AMs and LMVECs 
likely contributes to making the lungs a site of persistent infection in natural reservoir hosts $(10,11,19,29,31,68)$. Infection of these cells from rats results in production of SEOV particles, inhibition of proinflammatory responses, induction of regulatory responses, and induction of Treg cell activity. Future studies should identify the viral proteins and cellular pathways mediating the way in which SEOV induces PD-L1 expression in rat LMVECs and Tgf $\beta$ expression in AMs. A possible effect of hantavirus infection on human endothelial cell PD-L1 expression has been proposed but not yet investigated (74). We hypothesize that differences in PD-L1 expression during hantavirus infection might underlie the drastic difference in hantavirus disease outcomes between humans and reservoir hosts.

\section{ACKNOWLEDGMENTS}

This work was supported by the W. Harry Feinstone endowment and SWHR Medtronic Award.

We thank Alan Scott, Andrew Pekosz, and members of the Virology Laboratory meeting group for helpful discussions about these data.

\section{REFERENCES}

1. Alard P, Clark SL, Kosiewicz MM. 2004. Mechanisms of tolerance induced by TGF beta-treated APC: CD4 regulatory T cells prevent the induction of the immune response possibly through a mechanism involving TGF beta. Eur. J. Immunol. 34:1021-1030.

2. Au RY, Jedlicka AE, Li W, Pekosz A, Klein SL. 2010. Seoul virus suppresses NF-kappaB-mediated inflammatory responses of antigen presenting cells from Norway rats. Virology 400:115-127.

3. Barber DL, et al. 2006. Restoring function in exhausted CD8 T cells during chronic viral infection. Nature 439:682-687.

4. Bas A, Forsberg G, Hammarstrom S, Hammarstrom ML. 2004. Utility of the housekeeping genes $18 \mathrm{~S}$ rRNA, beta-actin and glyceraldehyde-3phosphate-dehydrogenase for normalization in real-time quantitative reverse transcriptase-polymerase chain reaction analysis of gene expression in human T lymphocytes. Scand. J. Immunol. 59:566-573.

5. Bjorkstrom NK, et al. 2011. Rapid expansion and long-term persistence of elevated NK cell numbers in humans infected with hantavirus. J. Exp. Med. 208:13-21.

6. Blackburn SD, et al. 2010. Tissue-specific differences in PD-1 and PD-L1 expression during chronic viral infection: implications for CD8 T-cell exhaustion. J. Virol. 84:2078-2089.

7. Blattman JN, Wherry EJ, Ha SJ, van der Most RG, Ahmed R. 2009. Impact of epitope escape on PD-1 expression and CD8 T-cell exhaustion during chronic infection. J. Virol. 83:4386-4394.

8. Boni C, et al. 2007. Characterization of hepatitis B virus (HBV)-specific T-cell dysfunction in chronic HBV infection. J. Virol. 81:4215-4225.

9. Borges AA, et al. 2008. Role of mixed Th1 and Th2 serum cytokines on pathogenesis and prognosis of hantavirus pulmonary syndrome. Microbes Infect. 10:1150-1157.

10. Botten J, et al. 2000. Experimental infection model for Sin Nombre hantavirus in the deer mouse (Peromyscus maniculatus). Proc. Natl. Acad. Sci. U. S. A. 97:10578-10583.

11. Botten J, et al. 2003. Persistent Sin Nombre virus infection in the deer mouse (Peromyscus maniculatus) model: sites of replication and strandspecific expression. J. Virol. 77:1540-1550.

12. Cabrera R, et al. 2004. An immunomodulatory role for $\mathrm{CD} 4(+) \mathrm{CD} 25(+)$ regulatory $\mathrm{T}$ lymphocytes in hepatitis $\mathrm{C}$ virus infection. Hepatology 40:1062-1071.

13. Cavanaugh PG, Nicolson GL. 1989. Purification and some properties of a lung-derived growth factor that differentially stimulates the growth of tumor cells metastatic to the lung. Cancer Res. 49:3928-3933.

14. Chen LB, Yang WS. 1990. Abnormalities of T cell immunoregulation in hemorrhagic fever with renal syndrome. J. Infect. Dis. 161:1016-1019.

15. Childs JE, Glass GE, Korch GW, LeDuc JW. 1989. Effects of hantaviral infection on survival, growth and fertility in wild rat (Rattus norvegicus) populations of Baltimore, Maryland. J. Wildl. Dis. 25:469-476.

16. du Bois RM. 1985. The alveolar macrophage. Thorax 40:321-327.

17. Easterbrook JD, Klein SL. 2008. Immunological mechanisms mediating hantavirus persistence in rodent reservoirs. PLoS Pathog. 4:e1000172. doi: 10.1371/journal.ppat.1000172.

18. Easterbrook JD, Klein SL. 2008. Seoul virus enhances regulatory and reduces proinflammatory responses in male Norway rats. J. Med. Virol. 80:1308-1318.

19. Easterbrook JD, Zink MC, Klein SL. 2007. Regulatory T cells enhance persistence of the zoonotic pathogen Seoul virus in its reservoir host. Proc. Natl. Acad. Sci. U. S. A. 104:15502-15507.

20. Elliott LH, et al. 1994. Isolation of the causative agent of hantavirus pulmonary syndrome. Am. J. Trop. Med. Hyg. 51:102-108.

21. Fels AO, Cohn ZA. 1986. The alveolar macrophage. J. Appl. Physiol. 60:353-369.

22. Francisco LM, et al. 2009. PD-L1 regulates the development, maintenance, and function of induced regulatory T cells. J. Exp. Med. 206:30153029.

23. Freeman GJ, et al. 2000. Engagement of the PD-1 immunoinhibitory receptor by a novel $\mathrm{B} 7$ family member leads to negative regulation of lymphocyte activation. J. Exp. Med. 192:1027-1034.

24. Gavrilovskaya IN, Gorbunova EE, Mackow ER. 2010. Pathogenic hantaviruses direct the adherence of quiescent platelets to infected endothelial cells. J. Virol. 84:4832-4839.

25. Gavrilovskaya IN, Gorbunova EE, Mackow NA, Mackow ER. 2008 Hantaviruses direct endothelial cell permeability by sensitizing cells to the vascular permeability factor VEGF, while angiopoietin 1 and sphingosine 1-phosphate inhibit hantavirus-directed permeability. J. Virol. 82:57975806.

26. Hall CH, Kassel R, Tacke RS, Hahn YS. 2010. HCV+ hepatocytes induce human regulatory CD4 $+\mathrm{T}$ cells through the production of TGF-beta. PLoS One 5:e12154. doi:10.1371/journal.pone.0012154.

27. Hannah MF, Bajic VB, Klein SL. 2008. Sex differences in the recognition of and innate antiviral responses to Seoul virus in Norway rats. Brain Behav. Immun. 22:503-516.

28. Hoshino Y, et al. 2007. Mechanisms of polymorphonuclear neutrophilmediated induction of HIV-1 replication in macrophages during pulmonary tuberculosis. J. Infect. Dis. 195:1303-1310.

29. Hutchinson KL, Rollin PE, Peters CJ. 1998. Pathogenesis of a North American hantavirus, Black Creek Canal virus, in experimentally infected Sigmodon hispidus. Am. J. Trop. Med. Hyg. 59:58-65.

30. Jiang H, et al. 2008. Hantaan virus induces toll-like receptor 4 expression, leading to enhanced production of beta interferon, interleukin- 6 and tumor necrosis factor-alpha. Virology 380:52-59.

31. Kariwa H, et al. 1996. Modes of Seoul virus infections: persistency in newborn rats and transiency in adult rats. Arch. Virol. 141:2327-2338.

32. Keir ME, et al. 2006. Tissue expression of PD-L1 mediates peripheral T cell tolerance. J. Exp. Med. 203:883-895.

33. Khaiboullina SF, Netski DM, Krumpe P, St Jeor SC. 2000. Effects of tumor necrosis factor alpha on sin nombre virus infection in vitro. J. Virol. 74:11966-11971.

34. Khaiboullina SF, St Jeor SC. 2002. Hantavirus immunology. Viral Immunol. 15:609-625.

35. Kilpatrick ED, et al. 2004. Role of specific CD8 + T cells in the severity of a fulminant zoonotic viral hemorrhagic fever, hantavirus pulmonary syndrome. J. Immunol. 172:3297-3304.

36. Kitamura T, et al. 1983. Isolation of virus causing hemorrhagic fever with renal syndrome (HFRS) through a cell culture system. Jpn. J. Med. Sci. Biol. 36:17-25.

37. Klein SL, et al. 2004. Differential expression of immunoregulatory genes in male and female Norway rats following infection with Seoul virus. J. Med. Virol. 74:180-190.

38. Kosiewicz MM, Alard P. 2004. Tolerogenic antigen-presenting cells: regulation of the immune response by TGF-beta-treated antigen-presenting cells. Immunol. Res. 30:155-170.

39. Kraus AA, Priemer C, Heider H, Kruger DH, Ulrich R. 2005. Inactivation of Hantaan virus-containing samples for subsequent investigations outside biosafety level 3 facilities. Intervirology 48:255-261.

40. Kraus AA, et al. 2004. Differential antiviral response of endothelial cells after infection with pathogenic and nonpathogenic hantaviruses. J. Virol. 78:6143-6150.

41. Krupnick AS, et al. 2005. Murine vascular endothelium activates and induces the generation of allogeneic CD $4+25+$ Foxp $3+$ regulatory $\mathrm{T}$ cells. J. Immunol. 175:6265-6270.

42. Lambrecht BN. 2006. Alveolar macrophage in the driver's seat. Immunity $24: 366-368$. 
43. Lee PW, Yanagihara R, Gibbs CJ, Jr, Gajdusek DC. 1986. Pathogenesis of experimental Hantaan virus infection in laboratory rats. Arch. Virol. 88:57-66.

44. Linderholm M, Ahlm C, Settergren B, Waage A, Tarnvik A. 1996. Elevated plasma levels of tumor necrosis factor (TNF)-alpha, soluble TNF receptors, interleukin (IL)-6, and IL-10 in patients with hemorrhagic fever with renal syndrome. J. Infect. Dis. 173:38-43.

45. Maes P, Clement J, Gavrilovskaya I, Van Ranst M. 2004. Hantaviruses: immunology, treatment, and prevention. Viral Immunol. 17:481-497.

46. Maier H, Isogawa M, Freeman GJ, Chisari FV. 2007. PD-1:PD-L1 interactions contribute to the functional suppression of virus-specific CD8+ T lymphocytes in the liver. J. Immunol. 178:2714-2720.

47. Markotic A, et al. 1999. Role of peripheral blood mononuclear cell (PBMC) phenotype changes in the pathogenesis of haemorrhagic fever with renal syndrome (HFRS). Clin. Exp. Immunol. 115:329-334.

48. Marsac D, et al. 2011. Infection of human monocyte-derived dendritic cells by ANDES Hantavirus enhances pro-inflammatory state, the secretion of active MMP-9 and indirectly enhances endothelial permeability. Virol. J. 8:223.

49. Mori M, et al. 1999. High levels of cytokine-producing cells in the lung tissues of patients with fatal hantavirus pulmonary syndrome. J. Infect. Dis. 179:295-302.

50. Mueller SN, et al. 2010. PD-L1 has distinct functions in hematopoietic and nonhematopoietic cells in regulating $\mathrm{T}$ cell responses during chronic infection in mice. J. Clin. Invest. 120:2508-2515.

51. Muhlbauer M, et al. 2006. PD-L1 is induced in hepatocytes by viral infection and by interferon-alpha and -gamma and mediates $\mathrm{T}$ cell apoptosis. J. Hepatol. 45:520-528.

52. Murphy J, Summer R, Wilson AA, Kotton DN, Fine A. 2008. The prolonged life-span of alveolar macrophages. Am. J. Respir. Cell Mol. Biol. 38:380-385.

53. Nagai T, et al. 1985. Isolation of haemorrhagic fever with renal syndrome virus from leukocytes of rats and virus replication in cultures of rat and human macrophages. J. Gen. Virol. 66:1271-1278.

54. Nakata K, et al. 1997. Mycobacterium tuberculosis enhances human immunodeficiency virus-1 replication in the lung. Am. J. Respir. Crit. Care Med. 155:996-1003.

55. Noone CM, et al. 2008. Natural killer cells regulate T-cell proliferation during human parainfluenza virus type 3 infection. J. Virol. 82:9299_ 9302.

56. Oh S, McCaffery JM, Eichelberger MC. 2000. Dose-dependent changes in influenza virus-infected dendritic cells result in increased allogeneic T-cell proliferation at low, but not high, doses of virus. J. Virol. 74:5460 5469.

57. Peng G, et al. 2008. PD-1 upregulation is associated with HBV-specific T cell dysfunction in chronic hepatitis B patients. Mol. Immunol. 45:963970.

58. Pensiero MN, Sharefkin JB, Dieffenbach CW, Hay J. 1992. Hantaan virus infection of human endothelial cells. J. Virol. 66:5929-5936.

59. Plekhova NG, et al. 2005. Metabolic activity of macrophages infected with hantavirus, an agent of hemorrhagic fever with renal syndrome. Biochemistry 70:990-997.

60. Prescott J, et al. 2010. New World hantaviruses activate IFNlambda production in type I IFN-deficient vero E6 cells. PLoS One 5:e11159. doi: 10.1371/journal.pone.0011159.

61. Quigley M, et al. 2010. Transcriptional analysis of HIV-specific CD8+ T cells shows that PD-1 inhibits T cell function by upregulating BATF. Nat. Med. 16:1147-1151.
62. Raftery MJ, Kraus AA, Ulrich R, Kruger DH, Schonrich G. 2002. Hantavirus infection of dendritic cells. J. Virol. 76:10724-10733.

63. Rehn B, Bruch J, Zou T, Hobusch G. 1992. Recovery of rat alveolar macrophages by bronchoalveolar lavage under normal and activated conditions. Environ. Health Perspect. 97:11-16.

64. Rowe RK, Suszko JW, Pekosz A. 2008. Roles for the recycling endosome, Rab8, and Rab11 in hantavirus release from epithelial cells. Virology 382: 239-249.

65. Safronetz D, et al. 2011. Pathogenesis and host response in Syrian hamsters following intranasal infection with Andes virus. PLoS Pathog. 7:e1002426. doi:10.1371/journal.ppat.1002426.

66. Sanduzzi A, Fraziano M, Mariani F. 2001. Monocytes/macrophages in HIV infection and tuberculosis. J. Biol. Regul. Homeost. Agents 15:294298.

67. Schonrich G, et al. 2008. Hantavirus-induced immunity in rodent reservoirs and humans. Immunol. Rev. 225:163-189.

68. Schountz T, et al. 2007. Regulatory T cell-like responses in deer mice persistently infected with Sin Nombre virus. Proc. Natl. Acad. Sci. U. S. A. 104:15496-15501.

69. Shrivastava-Ranjan P, Rollin PE, Spiropoulou CF. 2010. Andes virus disrupts the endothelial cell barrier by induction of vascular endothelial growth factor and downregulation of VE-cadherin. J. Virol. 84:1122711234

70. Stoltz M, et al. 2011. A model system for in vitro studies of bank vole borne viruses. PLoS One 6:e28992. doi:10.1371/journal.pone.0028992.

71. Sundstrom JB, et al. 2001. Hantavirus infection induces the expression of RANTES and IP-10 without causing increased permeability in human lung microvascular endothelial cells. J. Virol. 75:6070-6085.

72. Taflin C, et al. 2011. Human endothelial cells generate Th17 and regulatory T cells under inflammatory conditions. Proc. Natl. Acad. Sci. U. S. A. 108:2891-2896.

73. Temonen M, et al. 1993. Susceptibility of human cells to Puumala virus infection. J. Gen. Virol. 74:515-518.

74. Terajima M, Hayasaka D, Maeda K, Ennis FA. 2007. Immunopathogenesis of hantavirus pulmonary syndrome and hemorrhagic fever with renal syndrome: do CD8 + T cells trigger capillary leakage in viral hemorrhagic fevers? Immunol. Lett. 113:117-120.

75. Urbani S, et al. 2006. PD-1 expression in acute hepatitis C virus (HCV) infection is associated with HCV-specific CD8 exhaustion. J. Virol. 80: $11398-11403$

76. Walker JD, Maier CL, Pober JS. 2009. Cytomegalovirus-infected human endothelial cells can stimulate allogeneic CD4+ memory $\mathrm{T}$ cells by releasing antigenic exosomes. J. Immunol. 182:1548-1559.

77. Wewers MD, Rennard SI, Hance AJ, Bitterman PB, Crystal RG. 1984. Normal human alveolar macrophages obtained by bronchoalveolar lavage have a limited capacity to release interleukin-1. J. Clin. Invest. 74:2208 2218.

78. Yanagihara R, Amyx HL, Gajdusek DC. 1985. Experimental infection with Puumala virus, the etiologic agent of nephropathia epidemica, in bank voles (Clethrionomys glareolus). J. Virol. 55:34-38.

79. Yang G, et al. 2007. Association of CD4+CD25+Foxp3+ regulatory T cells with chronic activity and viral clearance in patients with hepatitis $\mathrm{B}$. Int. Immunol. 19:133-140.

80. Yoshizawa K, et al. 2010. Expansion of CD4(+)CD25(+)FoxP3(+) regulatory $\mathrm{T}$ cells in hepatitis $\mathrm{C}$ virus-related chronic hepatitis, cirrhosis and hepatocellular carcinoma. Hepatol Res. 40:179-187.

81. Zhu LY, Chi LJ, Wang X, Zhou H. 2009. Reduced circulating $\mathrm{CD} 4+\mathrm{CD} 25+$ cell populations in haemorrhagic fever with renal syndrome. Clin. Exp. Immunol. 156:88-96. 